Тамара Анатольевна Буданова

Финляндия, Университет г. Турку

\title{
Особенности пунктуации при слове действительно
}

Ключевые слова: вводное слово, пунктуация, дискурсивное слово, прагматикализация, сфера действия.

Key words: parenthetical word, punctuation, discourse word, pragmaticalization, scope of application.

\section{Abstract}

The paper examines punctuation features of the word dejstvitel'no. It is suggested that tendencies in using punctuation marks to single it out in texts correlate with the context determined by functional polysemy of discourse words.

Мы ставим перед собой задачу проанализировать вводные и не вводные употребления слова действительно с целью определения факторов, влияющих на пунктуацию. Материалом исследования послужили контексты употребления действительно, извлеченные из Национального корпуса русского языка (НКРЯ). В центре нашего внимания в данной статье находятся различия графического оформления типа:

1. Вы же ботаник, у «Контумакса», действительно, листья, как у георгина [Дудинцев].

2. Потому что у этой картошки действительно вкус был необыкновенный [Дудинцев].

\section{1. Вводные слова}

Действительно относят к многочисленной группе языковых единиц, способных употребляться в качестве вводных. Статус вводного слова (и словосочетания) 
как компонента предложения был установлен в русистике в середине прошлого века, и с тех пор по этому вопросу было достигнуто относительное согласие.

Вводными являются слова, сочетания слов, а также предложения, выражающие отношение говорящего к высказанному. Вводные конструкции дают общую оценку сообщения, указывают на источник и способ сообщения, связь с контекстом, порядок следования компонентов высказывания и т.д. Основное значение вводных конструкций - значение модальной, эмоциональной, экспрессивной оценочности [Valgina, Svetlyševa 2002].

Списки и классификации вводных слов предлагались неоднократно. Действительно относили к группе вводных слов, появившихся в русском языке в XVIII в. для выражения уверенности [Ickovič 1959], считали актуальным для характеристики высказывания с точки зрения его достоверности и способным указывать на отношение подтверждения [Ostanin 1969], причисляли к метатекстовым элементам, служащим для подтверждения ранее высказанной мысли [Kornilov 2003].

Согласно правилам русской пунктуации, в тексте вводные слова выделяются знаками препинания, чаще всего запятыми. Ситуации, когда «в зависимости от контекста одни и те же слова выступают то в качестве членов предложения, то в роли вводных слов (следовательно, не членов предложения)» [Rozental' 1985], традиционно относятся к трудным вопросам пунктуации. Знакомый со школьных лет способ проверки путем изъятия слова из предложения или его перемещения [Drugovejko-Dolžanskaâ, Gekkina, Belokurova, Belokurov 2007] в случае с действительно оказывается, на наш взгляд, неэффективным: структура предложения не распадается ни без члена предложения, ни без вводного слова, хотя значение высказывания подвергается определенной деформации, ср.

И здесь действительно море бирюзового цвета! - И здесь море бирюзового цвета! Небо, действительно, потемнело. - Небо потемнело.

Таким образом, существующие правила пунктуации не дают пишущему чётких критериев выделения действительно запятыми. Об этом говорит и тот факт, что запрос типа «действительно нужны ли запятые» является весьма частотным в поисковиках Рунета.

В стремлении найти ответы на «вечные» вопросы исследователи нередко выходят за рамки традиционной лингвистики, расширяют её границы, пробуют рассматривать привычные объекты изучения под иным углом зрения. Так, вводные и не вводные употребления слов анализируются в работах, посвященных изучению дискурсивных слов. 


\section{2. Дискурсивные слова}

Под этим термином поднимаются языковые единицы (отдельные слова и обороты), которые передают в большей степени отношения между элементами структуры дискурса, понимаемого как коммуникативная ситуация, включающая сознание коммуникантов и создающийся в процессе общения текст, нежели отношения между элементами описываемого в высказывании фрагмента действительности [Kibrik 1992: 289]. Хотя изучение дискурсивных слов ${ }^{1}$ началось не так давно, количество лингвистических работ, авторы которых анализируют дискурсивно-прагматические функции различных языковых единиц, позволяет говорить о том, что в рамках русистики сформировалось отдельное перспективное направление [например, Baranov, Plungân, Rahilina 1993; Kiseleva, Pajâr 2003]. Вместе с тем нельзя не признать, что выделение ДС как класса до сих пор остается дискуссионным вопросом. Споры вызывают прежде всего критерии отнесения слова или оборота к ДС: определяющей становится функционально-семантическая специфика, формальные характеристики при этом не имеют существенного значения. В результате образуется класс, не имеющий четких границ и объединяющий единицы, которые традиционно относятся к различным частям речи.

Стремление классифицировать растущий на наших глазах класс языковых единиц в рамках традиционной уровневой лингвистики вполне закономерно, поскольку поиски места в сложившейся иерархической структуре для каждого с трудом поддающегося описанию объекта являются одной из постоянных проблем языкознания. Как справедливо заметил Ю.П. Князев, идея существования слов, стоящих вне частей речи, не является популярной, и, чаще всего в неявной форме, предполагается, что все без исключения слова должны быть отнесены к какой-нибудь части речи [Knâzev 2001]. Многие исследователи отмечают, что ядро класса ДС составляют модальные и вводные слова. Конкретная же единица может классифицироваться авторитетными источниками по-разному. Так, словарные статьи, посвященные действительно, несколько расходятся в определение его частеречной принадлежности.

ДЕЙСТВИ́ТЕЛЬНО

I. нареч.

1. Употребляется как вводное слово, соответствуя по значению сл.: на самом деле.

II. частица разг.

1. Да, так, верно, точно.

2. Употребляется как вводное слово, выражая подтверждение [Efremova 2000].

${ }^{1}$ Далее - ДС. 
ДЕЙСТВИ́ТЕЛЬНО

I. нареч. В действительности, подлинно, в самом деле. Он д. очень устал.

II. вводн. сл. Подтверждает чью-л. мысль, выражает уверенность в чём-л. На этот раз, д., он прав.

III. частица. Употр. для выражения утверждения; да, верно. Он так сказал? Д. [Kuznecov 1998]

Наряду с транскатегориальностью осложняют изучения ДС и такие их свойства, как синкретичность и полифункциональность [Viktorova 2014], тесная связь с контекстом, способность к дискурсивному и не дискурсивному употреблению. До сих пор не разработан метод описания прагматикализации, в ходе которой у ДС в определенных контекстах прагматическое значение начинает преобладать над лексико-грамматическим, при этом в других контекстах этого не происходит.

\section{3. Группа ДС верификаторов}

Исследователями предлагается классификация ДС на основании их функции в дискурсе или некоего «общего значения». Так, действительно описывалось как один из элементов группы ДС, связанных с идеей «реальности». Также в эту группу вошли в самом деле, на самом деле, в действительности [Baranov, Plungân, Rahilina 1993: 76-104]. Представленная в издании модель описания ДС являлась одним из этапов разработки методологии контекстно-семантического подхода, который реализуется в совместном проекте французских и российских лингвистов по исследованию русских дискурсивных слов. В основу подхода положена идея варьирования плана содержания слова под влиянием факторов контекста. Для каждого ДС определены операция и их модификации, а также описаны соответствующие семантические эффекты. В качестве объединяющего группу основания предлагается идея оценки истинности или реальности исходно заданной ситуации Р. Используя эти единицы по отношению к Р, говорящий определяет, существует ли данная ситуация в реальности, т.е. производит оценку ее «реальности». В случае положительной оценки, элементы группы выражают подтверждение того, что ситуация имеет место в реальном мире, в противном случае - опровержение и истинность некоторого иного мнения.

Логично предположить, что операции ДС одной группы должны быть сходны. Так и оказывается: действительно и в самом деле указывают, что неочевидная или вызывающая сомнение с точки зрения своей обоснованности ситуация Р представляется говорящему бесспорной, в то время как с помощью на самом деле и в действительности говорящий, исходя из своих представлений о действительности, констатирует, что некоторая ранее заданная ситуация 
обладает статусом реальности. На основании этого в завершении анализа единицы делятся на два подкласса: ДС первого используются в контекстах подтверждения заданного высказывания, где Р - утверждение, вызывающее сомнение, тогда как элементы второго могут употребляться в контекстах опровержения, в которых Р не существует в реальном мире.

Модификации могут не менять основной операции, но при этом производить определенные семантические эффекты. Так, действительно выступает в качестве маркера подтверждения, если его употребление предполагает, что отсутствующее эксплицитно в предыдущем контексте высказывание Р уже актуализировано в сознании адресата. На самом деле производит «процедуру подтверждения», убеждая говорящего в Р, которое эксплицитно или имплицитно было введено как гипотеза в предыдущем контексте. Однако в большинстве случаев модификации вносят изменения в основной сценарий, вводя высказывания или объекты, выражая отношение говорящего к ситуации, его представление о ней. Это может быть, как в случае в ДС действительно и в самом деле, введение высказывания Q, которое сообщает, что неочевидное ранее Р представляется говорящему несомненным. Введение ситуации Q с помощью ДС на самом деле и в действительности также служит приписыванию ситуации Р статуса реальной, но при этом опровергается реальность Q.

На основании семантической близости и общих особенностей функционирования может быть выделена группа ДС верификаторов: в действительности, впрямь, в самом деле, действительно, и правда, на самом деле $e^{2}$. Вносимая ими в высказывание дискурсивная семантика является семантикой подтверждения, или верификации. В общем виде верификация представляет собой проверку истинности, установление достоверности и формируется по модели вопросно-ответное единства, диалога, в котором инициативная реплика - это запрос верификации, а реактивная - подтверждение или опровержение. Необходимо заметить, что речь идет о диалогичности в понимании М.М. Бахтина:

Отношения между репликами [...] диалога являются наиболее внешне наглядным и простым видом диалогических отношений. Но диалогические отношения, конечно, отнюдь не совпадают с отношениями между репликами реального диалога, - они гораздо шире, разнообразнее и сложнее. Два высказывания, отдаленные друг от друга и во времени и в пространстве, ничего не знающие друг о друге, при смысловом сопоставлении обнаруживают диалогические отношения, если между ними есть хоть какая-нибудь смысловая конвергенция (хотя бы частичная общность темы, точки зрения и т.п.) [Bahtin 1997: 335].

Следует отметить, что используемые в статье термины «верификация» и «верификатор» не являются авторскими неологизмами. Так, в книге Т.Е. Янко «Коммуникативные стратегии русской речи» действительно наряду

2 Данный перечень не претендует на полноту. 
с правда, вправду, впрямь и некоторыми другими отнесено к словам верификации [Ânko 2001].

\section{4. Исследование}

Наиболее подробно позиции вводности и невводности ДС на примере действительно обсуждались в статье [Bonnot, Kodzasov 2001], где, кроме различий в интонационном и графическом оформлении, отмечается, что и фонетический облик данной единицы меняется в зависимости от того, какую из этих двух позиций она занимает. Однако интонационные и фонетические особенности, сопряженные с контекстными различиями, остались за рамками нашего исследования, основное внимание было сосредоточено на пунктуации.

Материалом исследования послужили контексты употребления ДС действительно, извлеченные из «Национального корпуса русского языка» (НКРЯ). $\mathrm{B}$ процессе создания своего подкорпуса для поиска метатекстовые признаки были сужены: было определено время создания текста и жанровые характеристики. Исследовательский подкорпус составили художественные тексты, созданные с 1900 по 2014 г. Его объем был равен 5968 документам, 8946904 предложениям, 86508218 словам. Перед началом сбора материала предполагалось, что ДС является частотным и что количество полученных контекстов может измеряться сотнями единиц. Поэтому для удобства оперирования таблицами Access и Excel поиск проводился поэтапно, т.е. параметр «год создания текста» задавался более узко: 1900-1950, 1951-2000, 2001-2014. В результате общее количество отобранных и проанализированных контекстов действительно составило 3979 единиц, что соответствует $27 \%$ всего исследовательского корпуса ДС верификаторов.

Цель исследования состояла в выявлении связи между семантическим варьированием ДС действительно и выделением его знаками препинания.

На первом этапе анализа все контексты употребления были разделены на 3 типа: запрос подтверждения (3), подтверждение (4) и опровержение (5):

3. - А вот, Грушенька эта... В розовой кофте... Жанна д’Арк из Столбцов... «Узнаю коней ретивых»... Как сказал господин поэт, Александр Пушкин. Вроде опускает глаза в тарелку. Мне жаль его. Я заметил: ему нравится Груша. Но он застенчив. Он не смеет к ней подойти. Он не знает, что и как ей сказать. Он барин... Может быть, она действительно кажется ему Жанной д’Арк? [Савинков]

4. Господи, какое же, действительно, дивное её сочинение! Сколько надо продумать, прочувствовать, как тяжело-тяжело должно быть на душе, чтобы написать так, как написала она! Вероятно на эту тему навел ее её любимец Надсон, его стихотворение: «Если душно тебе, если нет у тебя...» Как чудно 
разработала она этот сюжет! Какие теплые, художественные, полные грусти места! Мне плакать хотелось, слушая. После урока я не могла удержаться от желания крепко расцеловать ее.

- Вера, милая, как чудно, как дивно ты написала! - кинулась я к ней. - Да ведь ты поэт!

Она тихо улыбнулась.

- Почему поэт? Ведь это не фантазия, я действительно испытываю все это. Книга - мое счастье, моя отрада. А ты, разве и ты того же не переживаешь? [Новицкая]

5. - Х Хочу тебя уверить, досаждать себе волнением - больше нет нужды. Ведь ты везунчик, а этого достаточно, чтобы успокоиться.

— Вот уж действительно!.. - не без сарказма, отреагировал Эрик на околесицу черноволосого.

Слова пышущего энигматичностью мужчины показались Эрику абсурдными! Он дернулся, словно его облили холодной водой. Никакой он не везунчик, скорее несчастный подросток, которого преследовало нечто ужасное [Мишин].

Контексты распределились по типам следующим образом: запрос - 530 $(13,3 \%)$, подтверждение - $3390(85,2 \%)$ и опровержение - 59 (1,5\%). Эти результаты, с одной стороны, согласуются с уже сложившимся в литературе представлением, что для действительно характерен прежде всего контекст подтверждения [Baranov, Plungân, Rahilina 1993], но с другой стороны, свидетельствуют о том, что для этого ДС возможен и контекст опровержения. Такие контексты немногочисленны и могут служить как для выражения иронического согласия, так и для выражения иронии или даже сарказма по отношению к убежденности собеседника по какому-либо поводу, как в примере 5.

Следует отметить, что для остальных верификаторов (в действительности, впрямь, в самом деле, действительно, и правда, на самом деле) также характерны наличие одного преобладающего контекста и употребление во всех трех контекстах.

На втором этапе исследования устанавливалось соответствие между типами контекста ДС действительно и наличием или отсутствием пунктуационных знаков, которые признавались показателями вводности. В таблице 1 представлены полученные результаты.

\section{Таблица 1}

\begin{tabular}{|l|c|c|c|}
\hline & $\begin{array}{c}\text { Запрос } \\
\text { подтверждения }\end{array}$ & Подтверждение & Опровержение \\
\hline Вводность & $82(16 \%)$ & $903(27 \%)$ & $0(0 \%)$ \\
\hline Невводность & $448(84 \%)$ & $2487(73 \%)$ & $59(100 \%)$ \\
\hline Общее количество & $530(100 \%)$ & $3390(100 \%)$ & $59(100 \%)$ \\
\hline
\end{tabular}


Оказалось, что количество вводных употреблений действительно значительно меньше не вводных. Наиболее распространено вводное употребление ДС действительно в контекстах подтверждения:

6. Если бы не моя Саломея, то, поверьте, грубить Фузинати не посмела бы я, не достало бы духа. Ведь он никогда не забудет обиды. За спиной Саломеи, действительно, мне сам черт не страшен, потому что - только мигни я, она такого скандала наделает, аж в Монце будет слышно!.. Она да Мафальда первые у нас бойцы [Амфитеатров].

7. Александр пошел однажды к своему старому партийному товарищу, доктору Рубакину, с которым вместе судился и который только благодаря случайности избежал каторги. Его удивило, что Рубакин изменился. Живет широко. От партийной работы отстал, хотя иногда дает свою квартиру для партийных собраний, видимо в душе тяготясь этим. Рубакин, насмешливо улыбаясь, рассказал ему партийные сплетни, критически отнесся к надеждам на скорую революцию, которые еще живут у некоторых товарищей.

- Вообще, - заметил он, - вся серьезная публика давно от этого всего отошла. На партийной работе теперь подвизается молодежь. Старики разве изредка дают директивы.

К решению Александра идти на фронт он отнесся с усмешкой: Пожалуй, это, действительно, лучше, чем сидеть в Сибири [Кузьмина-Караваева].

В контекстах запроса верификации вводность также возможна:

8. Он вдруг искренне позавидовал трудникам, их редкой страсти и душевной отваге, что они вот с такой легкостью добровольно заточились в обветшавший монастырь, желая возродить его из погибели. И Бурнашову тоже захотелось жить здесь во имя неясного промысла и соизволенья, с любовью тратить свое ремесленное уменье на храмину, изукрашивая ее резьбою и изнуряя себя трудом. В этом, наверное, действительно, кроется счастье, если душа беспечальна и покойна? [Личутин]

Примеров вводного употребления ДС действительно в немногочисленных контекстах опровержения не оказалось.

Среди контекстов подтверждения особый интерес представляет группа контекстов, в которых действительно является иллокутивным показателем, как в приведенном ниже примере:

9. Товарищ Емельян - так у нас зовут вашего друга, - продолжал паренек, - перешел на нелегальное положение. Вам он советует уехать в деревню. Говорит, что вместе с солдатами, которые вернулись с войны, вы можете заняться работой с крестьянами. [...] Паренек ушел, а Матвей, прикрыв за ним дверь, сел к столу и задумался. Действительно, не пора ли податься в деревню [Марков].

Таким образом подтверждается значимость для говорящего предыдущей реплики собеседника. В качестве иллокутивного показателя действительно 
всегда выделяется графически. Именно этот тип контекстов дает наибольшее разнообразие знаков препинания: кроме запятых используются тире (10), восклицательный знак (11), многоточие (12).

10. - За что?

- За что? - живо переспросил Витюлек и встал, держа локоток на отлете. А действительно - за что? Кому, я спрашиваю вас, мешал голос из санузла? Звучный бархатный баритон - кому? [Лукин]

11. И вот нос шагает среди запахов, и каждый - словно облачко невидимых частиц. А в самом носу, между прочим, ДЕСЯТЬ МИЛЛИОНОВ специальных луковичек, и от них, как провода, тянутся ДЕСЯТЬ МИЛЛИОНОВ нервов. Да-а, не прост наш нос! Стоит частице запаха сесть на луковичку, как по нервам к голове уже летит сигнал: борщ, борщ, борщ. И вот уже какой-нибудь Сенька несется на кухню. Сел, пододвинул тарелку... Стоп, стоп, при чём тут борщ? Действительно! Нос шел по лесу [Шац].

12. Сознайся! - Действительно... Я Скворушку в гости жду [Горланова].

В таких контекстах действительно функционирует аналогично коммуникативу (слову-предложению) да, отличаясь от последнего лишь, на наш взгляд, обязательным наличием правого контекста.

Поскольку в этом случае действительно занимает позицию в начале предложения, довольно часто это обстоятельство абсолютизируется как формальный критерий для постановки знака препинания. Однако в корпусе обнаружено некоторое количество примеров начальной позиции действительно при отсутствии знаков препинания.

13. - Моя машина вон там. Поехали.

- А... я живу далеко, на Просвете.

- Действительно далеко [Садулаев].

14. — Ты плачь! По-настоящему плачь! - учил Белорожий, - и проси, не отставай! Ругать будут - все равно проси! Как я! Я у мертвого выпрошу.

Действительно Белорожий у мертвого не у мертвого, а у переодетого городового (специально переодевались городовые для ловли нищих), три копейки на пирог выпросил [Андреев].

Представляется, что зависимость между положением действительно в начале предложения и его вводностью является скорее тенденцией, чем правилом.

В качестве существенной контекстной переменной, обусловливающей закономерности варьирования семантики ДС, называется актуализационная характеристика: дескрипция или актуальный комментарий. Разница между актуальным и дескриптивным статусом ДС отражается в интонационном оформлении и фиксируется в письменном тексте запятыми [Bonno, Kodzasov 1998].

Результаты исследования подтвердили, что действительно может выступать и как актуальный комментарий, и как дескрипция, однако не дали оснований утверждать, что существует устойчивая зависимость между его 
актуализационными характеристиками в конкретном контексте и наличием или отсутствием знаков препинания. Так, примеры 10 и 11 различаются пунктуационным оформлением без очевидных различий в актуализационном статусе.

15. Действительно, в потной его руке было три билета [Беляев].

16. Действительно в письме - на ощупь видно - больше слов и страниц, чем может вытянуть одна почтовая марка [Кржижановский].

Механизмы варьирования семантики ДС могут связываться со сферой действия ${ }^{3}$ [Bonno, Kodzasov 1998]. Понятие сферы действия введено в лингвистику И.М. Богуславским: с его помощью описывается определенная синтаксическая конструкция, необходимая для заполнения семантической валентности лексемы [Boguslavskij 1996]. В данной работе речь идет о ДС, среди употреблений которого есть и вводное, поэтому под СД подразумевается сфера прагматического действия. Сфера прагматического действия ДС действительно определяется тем объемом информации, которая вовлечена в ситуацию верификации. В зависимости от позиции, которую действительно занимает в предложении, его СД может быть различным, так как в процесс верификации может быть вовлечено как все высказывание, так и его отдельные фрагменты. Необходимо отметить, что в монографии «Дискурсивные слова русского языка» под СД понимается только актуализированный ДС фрагмент высказывания, который на синтаксическом уровне может представлять отдельную синтаксему, именную группу, глагольную группу, предложение в целом [Kiseleva, Pajâr 2003]. Однако анализ исследовательского материала показал, что СД действительно нередко выходит за пределы высказывания, непосредственно связанного с ДС и включает в себя левый и правый контекст, причем более широким и существенным для анализа является левый. Так, в приведенном ниже примере СД включает в себя достаточно широкий левый контекст.

17. Массы еще сверкали пламенем революции, но это не было жаркое пламя кокса, а жидкий огонь разлитого спирта, сгорающего, не успевая зажечь дерево, которое он облил. Таким огнем был Керенский. Я увидел в первый раз Керенского на его генеральной истерике; когда он после статьи в «Известиях», направленной против него, вбежал в Солдатский Совет спрашивать - «доверяют ли ему». Он бросал мятые фразы и, действительно, казался сверкающим сухими, длинными, трещащими искрами [Шкловский].

В результате СД дискурсивного слова оказывается значительно шире, чем отдельное предложение, в рамках которого действуют правила русской пунктуации.

\footnotetext{
${ }^{3}$ Далее-СД.
} 


\section{5. Пунктуация}

Знаки препинания, выделяющие вводные слова в предложении, относятся к «грамматическим» знакам, являющимся показателями синтактического, структурного членения письменной речи. Однако нередко происходит так, что доминировать начинает смысловое членение речи, подчиняя себе структурное. Знаки, отражающие смысловой принцип пунктуации, избираются в зависимости от конкретных задач высказывания и не регламентируются грамматическими условиями.

Современная русская пунктуация дает возможность передавать богатство и разнообразие смысловых оттенков и эмоций посредством принципов смыслового и интонационного, связанных с задачами актуализации, подчеркивания значений в тексте.

Анализируя использование знаков препинания в корпусе текстов, датированных 1900-2014 гг., можно сделать некоторые предварительные выводы о частотности выделения знаками препинания ДС действительно в разные периоды времени.

Таблица 2

\begin{tabular}{|c|c|c|c|c|}
\hline & $1900-1950$ & $1951-1975$ & $1976-1999$ & $2000-2014$ \\
\hline Вводность & $321(32 \%)$ & $219(22 \%)$ & $270(27 \%)$ & $175(17 \%)$ \\
\hline Всего & $993(100 \%)$ & $980(100 \%)$ & $995(100 \%)$ & $1011(100 \%)$ \\
\hline
\end{tabular}

В первой половине XX в. процент вводного употребления действительно относительно общего количества употреблений оказался наиболее высоким, а в начале $\mathrm{XX}$ - самым низким.

Вероятно, один из аспектов функционирования ДС - частотность употребления в позиции вводности - определяется в том числе и временным фактором.

Поскольку исследовательский корпус составили произведения художественной литературы, созданные 785 писателями, следует учитывать и возможность авторской пунктуации, под которой понимаются особенности пунктуационного оформления текстов, носящие индивидуальный характер, присущие тому или иному писателю (набор применяемых им знаков препинания, преимущественное использование одного из них, расширение функций этого знака), в целом не противоречащие принятым в данный период правилам. Авторская пунктуация - сознательное отступление от действующих норм пунктуации, оправданное стилем, жанром [Rozental' 1985]. Анализ контекстов из произведений писателей, которые чаще других использовали действительно (М. Горького, Е. Парнова, А.Н. Толстого, В.К. Арсеньева, М.А. Булгакова, 
Л.А. Чарской и С.Н. Сергеева-Ценского), не позволяет сделать выводы об авторской пунктуации и особенностях идиостиля на основании вводного и не вводного употребления одного ДС.

\section{6. Выводы}

На примере ДС действительно можно убедиться в том, что существует определенная зависимость между типом дискурсивного контекста и вводным/не вводным употреблением ДС.

Употребление ДС во многом определяется коммуникативными потребностями говорящего, который в зависимости от своих интенций может актуализировать различные компоненты содержания ДС. Но рамки подобного варьирования определяются контекстом, который может усиливать или нейтрализовать эти компоненты, используя для этих целей и знаки препинания.

Вместе с тем в настоящее время нет достаточной доказательной базы для того, чтобы принять наличие или отсутствие знаков препинания в качестве универсального формального критерия для определения семантических вариантов ДС. Этот критерий следует считать находящимся в начальной стадии разработки, которую значительно затрудняет многозначность текста, допускающая различные интерпретации и авторскую пунктуацию.

Дальнейшие исследования в этой области могли бы послужить уточнению существующих правил пунктуации при вводных словах, которые вызывают затруднения у пишущих.

\section{Литература}

Ânko T., 2001, Kommunikativnye strategii russkoj reči, Moskva: Âzyki slavânskoj kul'tury. Bahtin M., 1997, 1961 god. Zametki [in:] M. Bahtin, Sobranie sočinenij, vol. 5, Moskva: Russkie slovari, pp. 331-360.

Baranov A., Plungân V., Rahilina E. (eds.), 1993, Putevoditel' po diskursivnym slovam russkogo âzyka, Moskva: Pomovskij i partnery.

Boguslavskij I., 1996, Sfera dejstviâ leksičeskih edinic, Moskva: Âzyki russkoj kul'tury.

Bonnot K., Kodzasov S., 1998, Semantičeskoe var'irovanie diskursivnyh slov i ego vliânie na linearizaciû i intonirovanie (na primere častic že i ved') [in:] K. Kiseleva, D. Pajâr (eds.), Diskursivnye slovarusskogo âzyka: opyt kontekstual'no-semantičeskogo opisaniâ, Moskva: Metatekst, pp. 382-443.

Bonnot K., Kodzasov S., 2001, L'emploi des mot du discours en position détachéé et non détachéé (sur l'exemple de dejstvitel'no) [in:] M. Guiraud-Weber, I. Šatunovskij (eds.), Russkij âzyk: peresekaâ granicy, Dubna, pp. 28-42. 
Drugovejko-Dolžanskaâ S., Gekkina E., Belokurova S., Belokurov A., 2007, VVODNYE i NE VVODNYE, ili o različenii vvodnyh konstrukcij i členov predloženiâ [in:] Grammatika dialoga v russkom âzyke i literature, Sankt-Peterburg: MIRS, pp. 116-123.

Efremova T., 2000, Novyj slovar'russkogo âzyka. Tolkovo-slovoobrazovatel'nyj, Moskva: Russkij âzyk, https://www.efremova.info/word/dejstvitelno.html\#.Xt-iHjozbIU; 16.01.2019.

Ickovič V., 1959, Istoriâ vvodnyh slov i predloženij v russkom âzyke (materialy $k$ kursu istoričeskogo sintaksisa), L'vov: Izdatel'stvo L'vovskogo universiteta.

Kiseleva K., Pajâr D. (eds.), 2003, Diskursivnye slova russkogo âzyka: kontekstnoe var'irovanie i semantičeskoe edinstvo, Moskva: Azbukovnik.

Knâzev Û., 2001, O stat'e L.V. Serby «O častâh reči v russkom âzyke», http://www.ruthenia. $\mathrm{ru} / \mathrm{apr} / \mathrm{textes} / \mathrm{sherba/comm1.htm;} \mathrm{1.06.2020.}$

Kornilov A., 2003, Vvodnye elementy v russkoj reči, Sankt-Peterburg: Izdatel'stvo RGPU im. A.I. Gercena.

Kuznecov S. (ed.), 1998, Bol'šoj tolkovyj slovar'russkogo âzyka, http://endic.ru/kuzhecov/ Destvitelno-3369.html; 12.01.2019.

Ostanin A., 1969, Vvodnye slova i slovosočetaniâ v sovremennom russkom âzyke, Saratov: Izdatel'stvo SGPI.

Ostroumova O., Frampol' O., 2009, Slovar 'vvodnyh slov, sočetanij i predloženij, Saratov: Izdatel'stvo SGU.

Rozental' D., 1985, Spravočnik po pravopisanî̂ i literaturnoj pravke, Moskva: Kniga.

Valgina N., 1983, Trudnye voprosy punktuacii, Moskva: Prosveŝenie.

Viktorova E., 2014, Sinkretizm diskursivnyh slov, Izvestiâ saratovskogo universiteta, Novaâ seriâ. T. 14, Ser. Filologiâ. Žurnalistika, iss. 3, pp. 14-21. 